Open Access

\title{
Application of the ASVCP guidelines for the establishment of haematologic and biochemical reference intervals in Icelandic horses in Austria
}

Ernst F. Leidinger ${ }^{1 *}$, Judith Leidinger ${ }^{1}$, Julia Figl ${ }^{1}$, Bettina Rumpler ${ }^{2}$ and $\|$ se Schwendenwein $^{3}$

\begin{abstract}
Background: Despite the increasing popularity of Icelandic horses, published reference intervals (RIs) in this breed are rare. Due to their isolation and their small gene pool, alterations in some variables are likely and some possible breed-specific peculiarities have been described. The purpose of the present study was the establishment of comprehensive RIs in Icelandic horses according to recently published guidelines.

In a prospective observational study, blood samples were collected from the jugular vein of 142 Icelandic horses into EDTA and serum tubes. Reference intervals were established for haematologic and biochemical analytes on the Advia $2120 \mathrm{i}^{\mathrm{TM}}$ and the Dimension ExL ${ }^{\mathrm{TM}}$ by established methods. Rls were defined as central $95 \%$ intervals bounded by the 2.5 th and 97.5 th percentiles with their $90 \%$ confidence intervals, calculated according to recently published ASVCP guidelines. An inhouse-developed quality control system using observed total allowable error was used for the surveillance of the internal quality control preceding the measurements.
\end{abstract}

Results: The Rls were as follows: haematocrit: 0.29-0.39, RBC: 5.79-8.63 T//, haemoglobin: 102.0-142.3 g/l, MCV: $42-51$ fl, platelets: 146-263 G/I, WBC: 4.13-8.57 G/l, segs: 1.98-4.73 G/l, lymphocytes: 1.25-3.49 G/l, monocytes: 0.06-0.31 G/l, eosinophils: $0.04-0.50 \mathrm{G} / \mathrm{l}$, glucose: $4.0-5.7 \mathrm{mmol} / \mathrm{l}$, urea: $3.2-6.4 \mathrm{mmol} / \mathrm{l}$, creatinine: $79.6-141.4 \mu \mathrm{mol} / \mathrm{l}$, total protein: 54.4-72.9 $\mathrm{g} / \mathrm{l}$, albumin: 27.7-36.8 $\mathrm{g} / \mathrm{l}$, total bilirubin: 8.1-21.1 $\mu \mathrm{mol} / \mathrm{l}$, triglycerides: 0.03-0.44 mmol/I, cholesterol: $1.75-2.90 \mathrm{mmol} / \mathrm{I}, \mathrm{ALP}: 1.35-3.55 \mu \mathrm{kat} / \mathrm{l}, \mathrm{AST}: 4.52-8.80 \mu \mathrm{kat} / \mathrm{l}, \mathrm{GLDH}: 0.0-0.18 \mu \mathrm{kat} / \mathrm{l}, \mathrm{GGT}: 0.11-0.39$

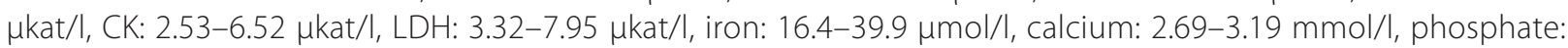
0.5-1.3 mmol/l, magnesium: 0.6-0.9 mmol/l, sodium: $134-141 \mathrm{mmol} / \mathrm{l}$, potassium: $3.6-4.7 \mathrm{mmol} / \mathrm{l}$, chloride: $100-105 \mathrm{mmol} / \mathrm{l}$.

Conclusions: Reference intervals of several haematologic and biochemical analytes differed from the transferred historical reference intervals applied to equine samples in the authors' laboratory. These might be of clinical importance in some analytes such as creatine kinase.

Keywords: Breed, Advia 2120i' ${ }^{\mathrm{TM}}$, Dimension ExL ${ }^{\mathrm{TM}}$, Reference population, Preanalytics, Comparison

\footnotetext{
* Correspondence: ernst.leidinger@invitro.at

1 In Vitro Veterinary Laboratories, Rennweg 95, 1030 Vienna, Austria

Full list of author information is available at the end of the article
} 


\section{Background}

Icelandic horses are small, long-living and robust. The average height at withers of the modern type is $136.4 \mathrm{~cm}$ (13.4 hands), established by video-morphometry [1]. They were bred completely isolated from other horse breeds for about a millennium and even today horses that have left Iceland are legally prevented from returning [2]. During the last four decades Icelandic horses have become increasingly popular as leisure and competition horses in many countries. The Icelandic horse studbook, 'WorldFengur', recorded more than 240,000 living Icelandic horses by October 2013 [3]. Intense selective pressures applied over time have resulted in substantial variation among horse breeds [4]. Statistically significant alterations of several haematologic and biochemical analytes have been described [5-7] and, therefore, divergent breed-related reference intervals (RIs) are to be expected $[8,9]$. For example, Icelandic horses reportedly have the lowest number of monocytes of all horse breeds (1.7-5.4\% or $0.10-0.45 \mathrm{G} / \mathrm{l})$ according to a recent study performed on the ADVIA 2120i haematology analyser [5]. Some studies found muscle enzyme activities that were significantly higher than in the general horse population $[5,10]$.

Unkel calculated RIs for a number of biochemical analytes for Icelandic horses. The RIs, however, were based upon a 16-84 \% interval which makes a comparison with more recently generated $95 \%$ population-based RIs difficult [11-13].

Recently breed-specific RIs have been established for three different horse breeds using the same haematology analyser (ADVIA) and a different chemistry analyser [5].

The purpose of the present study was to establish RIs specific for Icelandic horses that might be useful in improving the interpretation of laboratory test results. Comprehensive RIs for horses, regardless of breed, are rarely found in the peer-reviewed literature. The RIs were established by following the recently published guidelines of the American Society for Veterinary Clinical Pathology (ASVCP) [14, 15] with regards to the selection of the reference population, pre-analytical conditions, quality control, analytical conditions and statistical methods.

\section{Methods}

\section{Study population}

The study population was recruited from 4 stables in eastern Austria. All Icelandic horses were registered in Worldfengur database (www.Worldfengur.com). They were kept in paddocks year around with free access to shelter in a covered area. Only horses of 3 years or more were selected as Islandic horses are typically introduced into riding stables at an age of 3 years. In addition the following $a$ priori inclusion criteria were chosen: resident in Austria for more than 6 month, no gestation or lactation, and the absence of excessive exercise the day before the blood sampling. Clinical examination was based on visual examination, auscultation of the chest and heart and the body temperature. Blood was collected from 141 horses.

The study was approved by the Ethics Commission of the University of Veterinary Medicine, Vienna, Austria (license number 19/04/97/2013). The blood samples were taken with the owners' informed consent.

\section{Specimen collection}

Blood was collected for 2 days in February 2013 between 9:00 and 12:00 a.m., within 3 to $6 \mathrm{~h}$ after the morning feed. The left jugular vein was punctured by a $20 \mathrm{G}$ hypodermic needle and blood was allowed to flow freely along the vessel wall into the vial up to the filling mark.

Blood for the complete blood counts was collected into $4 \mathrm{ml}$ EDTA-K3 tubes (Vacuette, Greiner bio-one, Kremsmünster, Austria). Blood for biochemical analysis was collected into $10 \mathrm{ml}$ serum tubes with a clot activator and separator gel (Vacuette, Greiner bio-one, Kremsmünster, Austria). Blood was allowed to clot for $30 \mathrm{~min}$ at room temperature and then spun down for $10 \mathrm{~min}$ at $4200 \mathrm{RPM}(3800 \times g$, Universal 16 , Hettich, Tuttlingen, Germany).

Table 1 Analytical methods used on the ADVIA 2120i

\begin{tabular}{|c|c|c|c|}
\hline Analyte & Unit & Method & TEo (TEa) (\%) \\
\hline Haematocrit (Hct) & $|/|$ & Calculated from Hct, MCV & $3.7(10)$ \\
\hline Erythrocytes (RBC) & $\mathrm{T} / \mathrm{l}$ & Light scatter & $2.1(10)$ \\
\hline Haemoglobin (Hb) & $g / l$ & $\begin{array}{l}\text { Cyanide-free colorimetric } \\
\text { method }\end{array}$ & $1.9(10)$ \\
\hline $\mathrm{MCV}$ & $\mathrm{fl}$ & Light scatter/calculated & $1.9(7)$ \\
\hline $\mathrm{MCH}$ & $\mathrm{pg}$ & Calculated & NA \\
\hline $\mathrm{MCHC}$ & $g / l$ & Light scatter/calculated & $5.0(7)$ \\
\hline $\mathrm{CH}$ & $g / l$ & Light scatter/calculated & NA \\
\hline $\mathrm{CHCM}$ & $g / l$ & Light scatter/calculated & NA \\
\hline RDW & $\%$ & Light scatter/calculated & NA \\
\hline Platelets (PLT) & $\mathrm{G} / \mathrm{l}$ & Light scatter & $11.1(25)$ \\
\hline MPV & $\mathrm{fl}$ & Light scatter & NA \\
\hline WBC & $\mathrm{G} / \mathrm{l}$ & MP stain, light scatter & $10.2(15)$ \\
\hline MPXI & NU & $\begin{array}{l}\text { MP stain, light scatter, } \\
\text { calculated }\end{array}$ & NA \\
\hline $\begin{array}{l}\text { Automated } \\
\text { differential }\end{array}$ & $\mathrm{G} / \mathrm{l}$ & Light scatter & $\begin{array}{l}\text { All within } \\
\text { limits }\end{array}$ \\
\hline
\end{tabular}

$\mathrm{CH}$ cellular haemoglobin, $\mathrm{CHCM}$ corpuscular haemoglobin concentration, $\mathrm{Hct}$ haematocrit, $M C H$ mean cellular haemoglobin, $M C H C$ mean cellular haemoglobin concentration, $M C V$ : mean cellular volume, MP myeloperoxidase, MPXI myeloperoxidase index, NU no unit, NA not applicable, TEa total allowable error, TEo total observed error, RDW red blood cell distribution width 


\section{Haematological quality control (QC) and analysis}

All samples were analysed within $6 \mathrm{~h}$ of sampling.

The EDTA-samples were analysed on an ADVIA $2120 \mathrm{i}^{\mathrm{Tm}}$ (Siemens Healthcare Diagnostics, Vienna, Austria) with the multi-species software (version 5.3.1.-MS). The ADVIA $^{\mathrm{Tm}}$ system has recently been evaluated for the use in horses [16].

Three levels of quality control materials provided by the manufacturer (ADVIA ${ }^{\odot} 3$ in 1 TESTpoint $^{\mathrm{TM}}$ HematologyControls, Siemens Healthcare Diagnostics Inc., Tarrytown, NY, USA) were analysed daily according to the lab's working instructions. The units, methods used and the total observed error (TEo) are shown in Table 1. The TEo was compared to the total allowable error (TEa) [17] to determine whether the assay performance was satisfactory [18].

The RIs and the confidence intervals (CIs) were also calculated for several ADVIA ${ }^{\mathrm{Tm}}$-specific parameters: directly measured cellular haemoglobin $(\mathrm{CH})$, directly measured mean corpuscular haemoglobin concentration (CHCM) and myeloperoxidase index (MPXI). In addition, RIs were also established for the $\mathrm{Hct} / \mathrm{Hb}$ ratio.

\section{Biochemical QC and analysis}

All samples were analysed within $6 \mathrm{~h}$ of sampling.

The serum samples were analysed on the fully selective wet chemistry analyser Dimension ExL ${ }^{\mathrm{TM}}$ (Siemens Healthcare Diagnostics, Vienna, Austria). Two levels of quality control material (Liquid Assayed Multiqual ${ }^{\oplus}$, Bio-Rad Laboratories, Irvine, CA, USA, Cat. No. 694, 695) were analysed daily prior to running the samples. The units, methods and observed total error (TEo) results compared with the TEa are shown in Table 3 [19]. The reagents were ExL-specific (Siemens Healthcare Diagnostics, Vienna, Austria), with the exception of albumin and GLDH (Labor

Table 2 Analytical methods used on the Dimension ExL

\begin{tabular}{|c|c|c|c|}
\hline Analyte & Unit & Method & TEO (TEa) (\%) \\
\hline Glucose & $\mathrm{mmol} / \mathrm{l}$ & hexokinase-G6-PDG & $5.0(20)$ \\
\hline Urea & $\mathrm{mmol} / \mathrm{l}$ & enzymatic-kinetic UV-test with urease & $13.1(15)$ \\
\hline Creatinine & $\mu \mathrm{mol} / \mathrm{l}$ & picric acid & $13.3(20)$ \\
\hline Total protein & $g / l$ & biuret & $9.9(10)$ \\
\hline Albumin & $g / l$ & bromocresol green & $10.8(15)$ \\
\hline Bilirubin, total & $\mu \mathrm{mol} / \mathrm{l}$ & diazo-sulfaniline acid & $11.1(30)$ \\
\hline Bilirubin, direct & $\mu \mathrm{mol} / \mathrm{l}$ & diazo-sulfaniline acid/HCl & $37.3(35)$ \\
\hline Triglycerides & $\mathrm{mmol} / \mathrm{l}$ & 4-step, enzymatic & $10.2(25)$ \\
\hline Cholesterol & $\mathrm{mmol} / \mathrm{l}$ & cholesterol esterase/cholesterol oxidase & $6.6(20)$ \\
\hline Alkaline phosphatase (ALP) & $\mu k a t / I(I U / l)$ & IFCC, kinetic & $18.9(25)$ \\
\hline Aspartate aminotransferase (AST) & $\mu k a t / I(I U / l)$ & IFCC, with pyridoxale-phosphate activation & $9.1(30)$ \\
\hline Alanine aminotransferase (ALT) & $\mu k a t / I(I U / l)$ & IFCC, with pyridoxale phosphate activation & $23.0(25)$ \\
\hline Glutamate hydrogenase (GLDH) & $\mu \mathrm{kat} / \mathrm{I}(\mathrm{IU} / \mathrm{l})$ & DGKC, optimised & $45.1(30)$ \\
\hline Y-glutamyl transferase (GGT) & $\mu \mathrm{kat} / \mathrm{I}(\mathrm{IU} / \mathrm{l})$ & IFCC, kinetic & $21.9(20)$ \\
\hline Lipase & $\mu \mathrm{kat} / \mathrm{I}(\mathrm{IU} / \mathrm{l})$ & DGGR & $24.5(25)$ \\
\hline Creatine kinase (CK) & $\mu \mathrm{kat} / \mathrm{I}(\mathrm{IU} / \mathrm{l})$ & IFCC, kinetic & $7.1(30)$ \\
\hline Lactate dehydrogenase (LDH) & $\mu k a t / I(I U / l)$ & IFCC, kinetic & $8.7(20)$ \\
\hline Iron (Fe) & $\mu \mathrm{mol} / \mathrm{l}$ & Ferene & $6.3(30)$ \\
\hline Calcium (Ca) & $\mathrm{mmol} / \mathrm{l}$ & a-cresolpthaleine & $7.5(10)$ \\
\hline Phosphorus (P) & $\mathrm{mmol} / \mathrm{l}$ & phosphate-molybtate, modified & $10.2(15)$ \\
\hline Magnesium (Mg) & $\mathrm{mmol} / \mathrm{l}$ & methylthymol blue & $10.9(20)$ \\
\hline Sodium (Na) & $\mathrm{mmol} / \mathrm{l}$ & ISE & $3.3(5)$ \\
\hline Potassium (K) & $\mathrm{mmol} / \mathrm{l}$ & ISE & $7.3(5)$ \\
\hline Chloride $(\mathrm{Cl})$ & $\mathrm{mmol} / \mathrm{l}$ & ISE & $4.8(5)$ \\
\hline
\end{tabular}

The TEo in bold indicates that the value exceeded the ASVCP-recommended TEa during the period of analysis

DGKG Deutsche Gesellschaft für klinische Chemie, DGGR 1,2-o-dilauryl-rac-glycero glutaric; acid-(6'-methylresorufin), $\mathrm{HCl}$ hydrochloric acid, IFCC international federation for clinical chemistry, ISE ion selective electrode, PDG pyruvate dehydrogenase, TEa: total allowable error, TEo total observed error 
\& Technik, Berlin, Germany). Enzymes were measured at $37^{\circ} \mathrm{C}$.

The units, methods used and the total observed error (TEo) are shown in Table 2.

\section{Statistics}

The reference intervals were calculated following the ASVCP guidelines [14]. Normality was assessed by the Anderson-Darling test. Outliers were identified by Tukey and Dixon-Reed methods and were eliminated after visual inspection. Data analysis was performed by MS Excel (Microsoft, Redmond, WA, USA) with the macro-instruction set Reference Value Adviser v1.3 (Ecole Nationale Vétérinaire, Toulouse, France) according to published guidelines [20]. Depending on the distribution, the parametric or robust method with or without BoxCox transformation was applied to calculate the $95 \%$ population-based RIs.

Descriptive statistics were calculated by Analyze-It for MS Excel (Analyze-It Software Ltd, Leeds, UK).

Following the recommendations by the Clinical Laboratory Standards Institute (CLSI) and the International Federation for Clinical Chemistry (IFCC) [21], CI should not exceed 0.2 times (or 1/5) the width of the RI (WCI/WRI $<0.2$, where WCI is the width of the CI and WRI is the width of the RI).

\section{Results}

The median age of the reference animals was 13.7 years, the mean age 13.0 years and maximum age of 27 years.

Table 3 Reference limits and their Cls for haematology analytes; $n$ indicates the number of reference individuals after the removal of outliers, $\mathrm{Cl}$ width describes the width of the lower and upper reference limit in comparison to the width of the RIs

\begin{tabular}{|c|c|c|c|c|c|}
\hline Analyte & Number & $\begin{array}{l}\text { Reference } \\
\text { interval }\end{array}$ & $\begin{array}{l}\text { Cl lower } \\
\text { reference limit }\end{array}$ & $\begin{array}{l}\mathrm{Cl} \text { upper } \\
\text { reference limit }\end{array}$ & $\begin{array}{l}\text { Cl width ratios } \\
\text { LRL/URL }\end{array}$ \\
\hline Haematocrit & 132 & $0.29-0.39$ & $0.29-0.29$ & $0.38-0.40$ & $0.0 / 0.2$ \\
\hline $\mathrm{RBC}$ & 136 & $5.79-8.63$ & $5.48-5.98$ & $8.46-8.68$ & $0.2 / 0.1$ \\
\hline Haemoglobin & 134 & $102.0-142.3$ & $100.0-103.0$ & $137.0-145.0$ & $0.1 / 0.2$ \\
\hline $\mathrm{Hct} / \mathrm{Hb}$ & 131 & $2.72-2.88$ & $2.69-2.74$ & $2.87-2.89$ & $\mathbf{0 . 3} / 0.1$ \\
\hline $\mathrm{MCHC}$ & 137 & $347.0-366.6$ & $346.0-349.0$ & $364.0-369.0$ & $0.2 / \mathbf{0 . 3}$ \\
\hline $\mathrm{MCH}$ & 139 & 14.9-18.3 & $14.4-15.0$ & 18.0-18.8 & $0.2 / 0.2$ \\
\hline MCV & 138 & $42-51$ & $41-43$ & $50-52$ & $0.2 / 0.2$ \\
\hline $\mathrm{CH}$ & 137 & $151.9-184.1$ & $148.0-155.0$ & 181.0-187.0 & $0.2 / 0.2$ \\
\hline $\mathrm{CHCM}$ & 137 & $349.9-375.6$ & $348.0-352.0$ & $374.0-381.0$ & $0.2 / 0.2$ \\
\hline RDW & 139 & 16.8-19.6 & $16.3-16.9$ & $19.1-19.8$ & $0.2 / \mathbf{0 . 3}$ \\
\hline WBC & 138 & $4.13-8.57$ & $3.63-4.23$ & $8.20-8.83$ & $0.1 / 0.1$ \\
\hline Platelets & 135 & $146-263$ & $140-156$ & $256-282$ & $0.1 / 0.2$ \\
\hline MPV & 138 & $6.1-10.9$ & $6.1-6.3$ & $10.0-11.3$ & $0.0 / 0.3$ \\
\hline Segs (\%) & 138 & $37.8-67.7$ & $34.8-41.4$ & $64.9-69.6$ & $0.2 / 0.2$ \\
\hline Segs (abs) & 136 & $1.98-4.73$ & $1.83-2.28$ & $4.55-4.90$ & $0.2 / 0.1$ \\
\hline Lymphocytes (\%) & 136 & $25.7-52.1$ & $21.4-27.4$ & $50.9-54.2$ & $0.2 / 0.1$ \\
\hline Lymphocytes (abs) & 132 & $1.25-3.49$ & $1.01-1.40$ & $3.19-3.70$ & $0.2 / 0.2$ \\
\hline Monocytes (\%) & 137 & $1.2-4.4$ & $0.7-1.5$ & $4.0-4.9$ & $0.2 / 0.2$ \\
\hline Monocytes (abs) & 136 & $0.06-0.31$ & $0.05-0.07$ & $0.27-0.37$ & $0.1 / \mathbf{0 . 4}$ \\
\hline Eosinophils (\%) & 124 & $0.7-7.6$ & $0.5-1.1$ & $7.4-8.1$ & $0.1 / 0.2$ \\
\hline Eosinophils (abs) & 123 & $0.04-0.50$ & $0.03-0.07$ & $0.48-0.52$ & $0.1 / 0.1$ \\
\hline Basophils (\%) & 139 & $0.1-1.0$ & $0.1-0.2$ & $0.8-1.1$ & $0.1 / \mathbf{0 . 3}$ \\
\hline Basophils (abs) & 138 & $0.01-0.07$ & $0.00-0.01$ & $0.05-0.08$ & $0.1 / \mathbf{0 . 4}$ \\
\hline Large unstained cells (\%) & 139 & $0.1-0.5$ & $0.0-0.1$ & $0.4-0.6$ & $0.3 / 0.5$ \\
\hline Large unstained cells (abs) & 138 & $0.00-0.03$ & $0.00-0.01$ & $0.03-0.04$ & $0.2 / \mathbf{0 . 3}$ \\
\hline MPXI & 138 & $1.3-17.2$ & $0.6-2.4$ & $16.0-18.5$ & $0.1 / 0.2$ \\
\hline
\end{tabular}

Bold: ratio exceeded the desired maximum ratio $(<0.2)$

$C H$ cellular haemoglobin, $C H C M$ corpuscular haemoglobin concentration, $C l(s)$ confidence interval(s), $H b$ haemoglobin, $H c t$ haematocrit, $L R L$ lower reverence limit, $M C H$ mean cellular haemoglobin, $M C H C$ mean cellular haemoglobin concentration, MPV mean platelet volume, MP myeloperoxidase, MPXI myeloperoxidase index, $P L T$ platelets, $R B C$ red blood cells, RDW red blood cell distribution width, RI(s) reference interval(s), URL upper reference limit, WBC white blood cells 


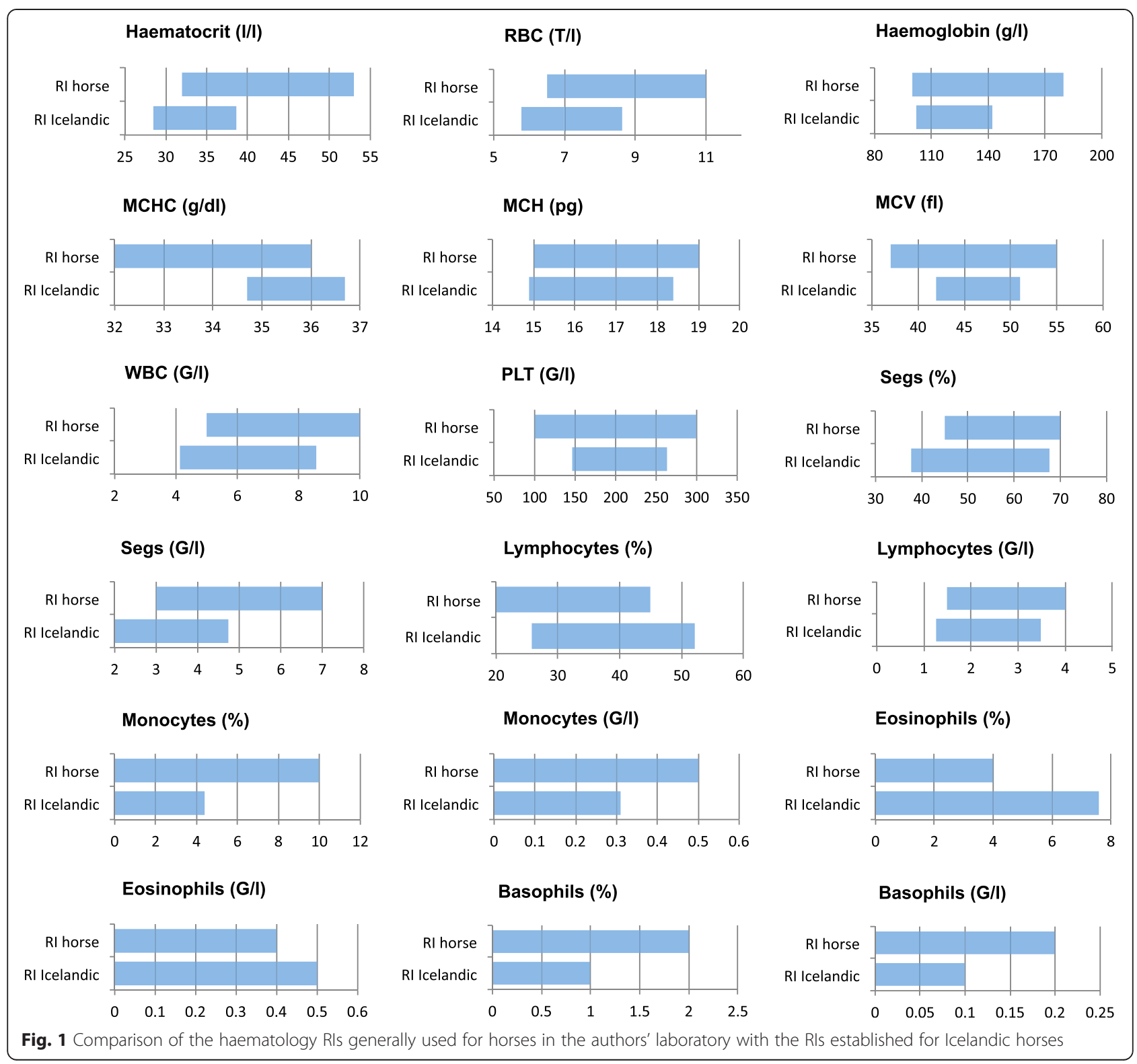

The population consisted of 88 geldings, 47 mares and 6 stallions. Two horses were excluded from the beginning due to elevated liver parameters.

\section{Haematology results}

All haematology analytes were calculated by the nonparametric method, because the required number of reference individuals $(n \geqq 120)$ was achieved. A normal distribution was observed with the following analytes: RBC, $\mathrm{MCHC}, \mathrm{MCH}, \mathrm{RDW}, \mathrm{MPV}$, Hct/Hb, and lymphocytes \%. Results and their CIs are summarised in Table 3. In Fig. 1 the calculated RIs are compared to the haematology RIs used for horses in the author's lab.

\section{Biochemistry results}

The RIs and the $90 \% \mathrm{CI}$ of the upper and lower RL for all biochemical analytes except potassium were calculated by the non-parametric method, because the required number of reference individuals $(n>120)$ was achieved. Potassium $(n=109)$ was calculated by the parametric method after Box-Cox transformation due to the large number of outliers which were excluded. The CIs were calculated by bootstrap. A normal distribution was observed with the following analytes: total protein, albumin, total bilirubin, triglycerides, cholesterol, AST, iron and calcium. The biochemistry RIs and their CIs are summarised in Table 4. In Fig. 2 the calculated RIs are compared to biochemistry RIs used for horses in the author's lab. 
Table 4 Reference limits and their confidence intervals for biochemical analytes; $n$ indicates the number of reference individuals after the removal of outliers, $\mathrm{Cl}$ width ratio describes the width of the lower and upper reference limit in comparison to the width of the Rls

\begin{tabular}{|c|c|c|c|c|c|}
\hline Analyte & Number & $\begin{array}{l}\text { Reference } \\
\text { interval }\end{array}$ & $\begin{array}{l}\text { Cl lower } \\
\text { reference limit }\end{array}$ & $\begin{array}{l}\mathrm{Cl} \text { upper } \\
\text { reference limit }\end{array}$ & $\begin{array}{l}\text { Cl width } \\
\text { ratio } \\
\text { LRL / URL }\end{array}$ \\
\hline Glucose & 135 & $4.0-5.7$ & $3.9-4.1$ & $5.5-5.8$ & $0.1 / 0.2$ \\
\hline Urea & 139 & $3.2-6.4$ & $3.0-3.5$ & $6.0-6.7$ & $0.2 / 0.2$ \\
\hline Creatinine & 137 & 79.6-141.4 & $79.6-88.4$ & $132.6-141.4$ & $0.1 / 0.1$ \\
\hline Total protein & 138 & $54.4-72.9$ & $53.1-55.5$ & 71.4-75.1 & $0.1 / 0.2$ \\
\hline Albumin & 132 & $27.7-36.8$ & $27.3-28.5$ & $35.4-37.2$ & $0.1 / 0.2$ \\
\hline Bilirubin, total & 132 & $8.1-21.1$ & $7.5-9.7$ & $20.2-22.4$ & $0.2 / 0.2$ \\
\hline Bilirubin, direct & 136 & $2.7-5.5$ & $2.6-2.9$ & $5.1-5.6$ & $0.1 / 0.1$ \\
\hline Triglycerides & 133 & $0.03-0.44$ & $0.01-0.06$ & $0.38-0.47$ & $0.1 / 0.2$ \\
\hline Cholesterol & 136 & $1.75-2.90$ & $1.68-1.81$ & $2.77-3.00$ & $0.1 / 0.2$ \\
\hline \multirow[t]{2}{*}{ ALP } & 135 & $1.35-3.55$ & $1.28-1.52$ & $3.45-3.67$ & $0.1 / 0.1$ \\
\hline & & $(81-213)$ & $(77-91)$ & $(207-220)$ & \\
\hline \multirow[t]{2}{*}{ AST } & 133 & $4.52-8.80$ & $3.85-4.82$ & $8.15-8.87$ & $0.2 / 0.2$ \\
\hline & & $(271-528)$ & $(231-289)$ & $(489-532)$ & \\
\hline \multirow[t]{2}{*}{ ALT } & 138 & $0.01-0.15$ & $0.0-0.02$ & $0.15-0.17$ & $0.1 / 0.1$ \\
\hline & & $(0.5-9.0)$ & $(0.0-1.0)$ & $(9.0-10.0)$ & \\
\hline \multirow[t]{2}{*}{ GLDH } & 132 & $0.0-0.18$ & $0.0-0.002$ & $0.16-0.19$ & $0.0 / 0.2$ \\
\hline & & $(0.0-10.7)$ & $(0.0-0.1)$ & $(9.4-11.5)$ & \\
\hline \multirow[t]{2}{*}{ GGT } & 127 & $0.11-0.39$ & $0.06-0.14$ & $0.36-0.40$ & $0.2 / 0.1$ \\
\hline & & $(6.6-23.6)$ & $(3.3-8.2)$ & $(21.4-23,8)$ & \\
\hline \multirow[t]{2}{*}{ Lipase } & 135 & $0.43-1.12$ & $0.38-0.47$ & $1.07-1.15$ & $0.1 / 0.1$ \\
\hline & & $(26-67)$ & $(23-28)$ & $(64-69)$ & \\
\hline \multirow[t]{2}{*}{ CK } & 134 & $2.53-6.52$ & $2.28-2.72$ & $5.92-6.57$ & $0.1 / 0.2$ \\
\hline & & $(152-391)$ & $(137-163)$ & $(355-394)$ & \\
\hline \multirow[t]{2}{*}{$\mathrm{LDH}$} & 136 & $3.32-7.95$ & $2.80-3.70$ & $7.65-8.17$ & $0.2 / 0.1$ \\
\hline & & $(199-477)$ & $(168-222)$ & $(459-490)$ & \\
\hline Iron (Fe) & 137 & $16.4-39.9$ & $14.7-21.7$ & $38.0-41.4$ & $0.3 / 0.1$ \\
\hline Calcium (Ca) & 139 & $2.69-3.19$ & $2.65-2.73$ & $3.16-3.25$ & $0.2 / 0.2$ \\
\hline Phosphate (P) & 139 & $0.5-1.3$ & $0.4-0.6$ & $1.3-1.5$ & $0.3 / 0.3$ \\
\hline Magnesium (Mg) & 138 & $0.6-0.9$ & $0.6-0.6$ & $0.9-0.9$ & $0.0 / 0.0$ \\
\hline Sodium (Na) & 138 & $134-141$ & 134-135 & $140-141$ & $0.2 / 0.2$ \\
\hline Potassium (K) & 109 & $3.6-4.7$ & $3.5-3.6$ & $4.6-4.8$ & $0.1 / 0.2$ \\
\hline Chloride (Cl) & 133 & 100-105 & 100-100 & 105-105 & $0.0 / 0.0$ \\
\hline
\end{tabular}

Bold: ratio exceeded the desired maximum ratio $(<0.2)$. Enzyme activities in brackets are in IU/I

$A L T$ alanine aminotransferase, $A P$ alkaline phosphatase, ASVCP american society for veterinary clinical pathology, $A S T$ aspartate aminotransferase, $C K$ creatine kinase, GGT Y-glutamyl transferase, GLDH glutamate hydrogenase, $L D H$ lactate dehydrogenase, $L R L$ lower reverence limit, $R I(s)$ reference interval(s), $U R L$ upper reference limit

\section{Discussion}

The aim of this prospective study was to establish comprehensive RIs with well characterised analytical methods in a population of Icelandic horses with a well defined health state and in accordance with recently published guidelines $[14,15,21]$. Haematological and biochemical RIs may vary with age, sex, and season [5, 22].
However, data were not stratified in our study because under the conditions the horses were kept, a homogenous distribution for the variables mentioned above could not be achieved. The horses were at least 3 years of age and many more geldings were represented compared to mares. However this is representative of the overall Icelandic horse population in eastern Austria. 


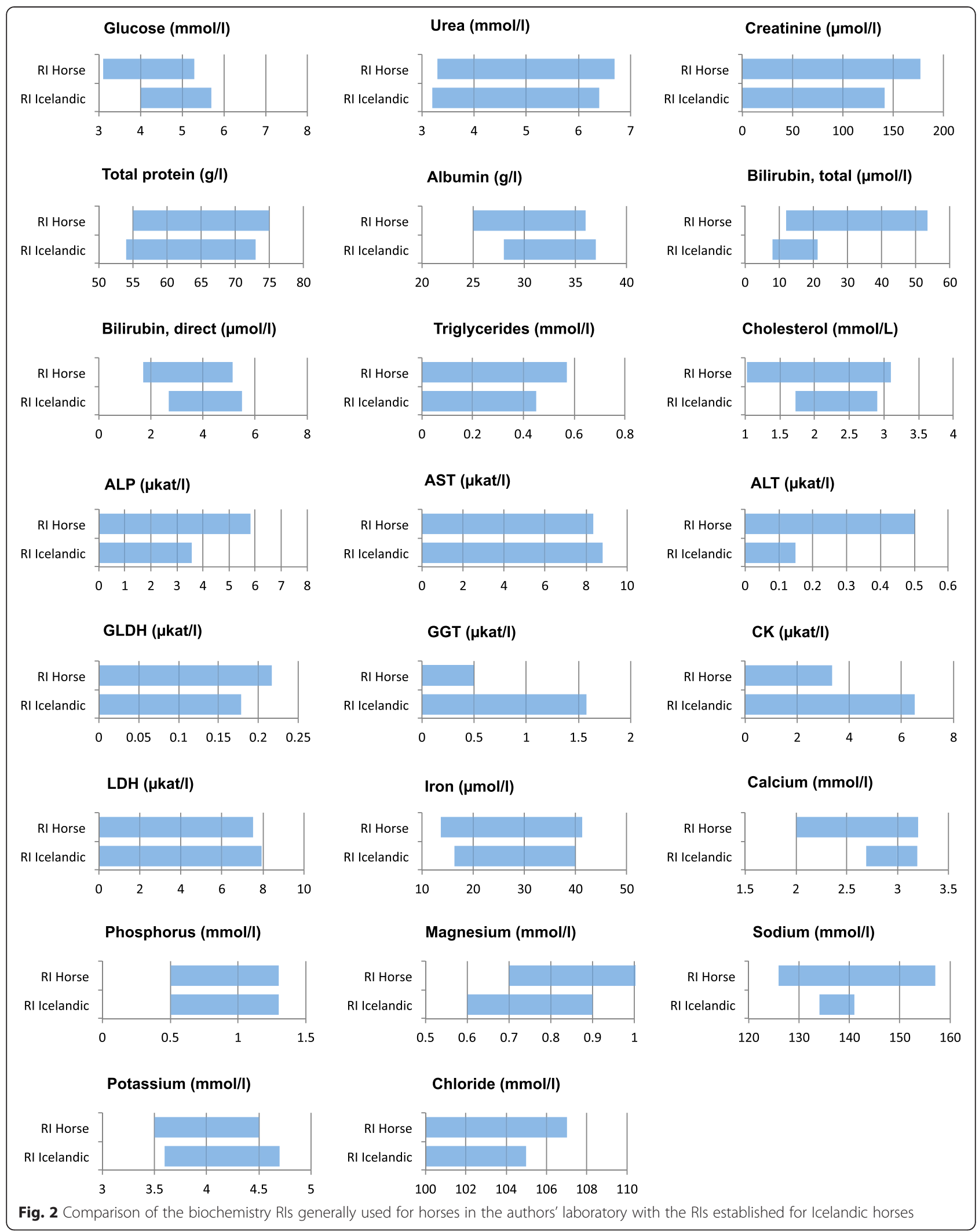


Furthermore, all horses in this study were registered in Worldfengur, where of approximately $35 \%$ were imported from Iceland directly. It is also know from genetic studies that very little variation was found between Icelandic horses in different countries [23]. Therefore, the RI established in our study most likely are also representative for the Islandic horse population in general, despite the under-representation of mares.

In addition to a reliable reference population, the quality specifications for the methods are of paramount importance for the reliability of the RIs [24], although QC data are rarely included in reports of RI studies. In one recent study, mean and coefficient of variation of analytes were presented [25]. Friedrichs et al. recommended the recording of the TEo for all methods [15]. In our study, all haematology analytes achieved the quality goals (Table 1). The TEo of a given biochemistry analyte was compared to the TEa recommended by the ASVCP guidelines on total error and was for most methods below the recommended limit [14]. The biochemical analytes direct bilirubin, potassium, and GLDH did not meet the analytical goals. The deviations for direct bilirubin and potassium were small; in the case of potassium, the TEo deviation was caused by a single QC value exceeding the 2 standard deviation range. The TEo for GLDH requires a more detailed consideration: while a TEo of $30 \%$ is typical for many enzymes, at a TEo of $45 \%$, a given value could be $45 \%$ higher or lower than the true activity. However GLDH is a reliable indicator of hepatocyte damage, hence it was decided to include the RIs for GLDH, because there are few reference intervals for this analyte in the peer-reviewed literature. The RIs compared well to other published values [5], and the CIs were reasonably narrow. Another source for poor method performance of these few analytes might be the instability of the QCmaterial suspected in 1 level in this study due to trend for decreasing values in results over time.

The most noticeable finding in the haematologic raw data was the high number of outliers for the eosinophil percentage. The Dixon and Turkey tests identified 15/ 139 values as outliers. With two exceptions, all animals with increased eosinophil proportions were from the same riding stable. The reason for these outliers is not known. All horses were clinical healthy and regularly dewormed, but the increase could reflect a subclinical parasitism or allergy [26]. In one study, increased eosinophil numbers were found in horses kept outdoors $24 \mathrm{~h}$ a day [27].

To establish a diagnosis of eosinophilia as well as the increase of other leukocyte fractions, only the absolute numbers must be considered [28, Additional file 1]. The relative numbers, however, are still widely used among referral laboratories and clinicians [29]. They are applied for manual differentials and for the analysers's internal quality control, and therefore reported in this study.
The RIs for Hct/Hb was included because it proved useful for the primary plausibility checks in our LIMS of haemograms measured on the ADVIA. According to our working instructions, a spun haematocrit is performed, if the ratio exceeds the lower or upper RL (unpublished data).

Haematologic RIs on the ADVIA for Icelandic horses were established in a previous study for 6 different horse breeds, including 84 Icelandic horses and used similar statistical methods [5]. While there was a good agreement in the overall data, differences were found for the following analytes: haematocrit, MCHC, MCV, WBC, platelets, lymphocytes (absolute) and eosinophils (relative and absolute). For $\mathrm{MCHC}$, much higher ranges were found in that and another study [28] with reference intervals of 40.8 to 44.1 and 35 to $42 \mathrm{~g} / \mathrm{l}$, respectively. The reason for this is not clear. Our $\mathrm{MCHC}$ values compared well to the directly measured $\mathrm{CHCM}$ values.

The MPXI seemed to be useful as additional inflammatory parameter for the diagnosis of sepsis in horses [30], but this could not be confirmed in another study [31].

This low monocyte count found by Gieseler, was confirmed by our data from the ADVIA differentials [5]. It may, however, be caused by the way the ADVIA displays the monocytes of Icelandic horses in the Perox channel, rather than by a breed-associated peculiarity [32]. However, the routine gating is likely to be applied since the manual gating, while not difficult, is time consuming.

Analysis of potassium data revealed 30/139 (21.6 \%) outliers, almost all of them from a single stable. The eliminated values exceeded the RIs given elsewhere [5]. Most likely this was caused by a pre-analytical problem, but a definitive reason for this finding was not identified. Potassium is contained in high concentrations in the equine RBCs, WBCs and PLT and can diffuse into serum [33]. The room temperature in the preparation room where the blood was left for clot formation could not be tightly controlled. No serum sample was visibly haemolysed, and no other analytes were affected.

In several publications, CK, AST and LDH activities were increased in Icelandic horses compared to standard and thoroughbred horses [10, 11, 34]. Other studies showed no increase in liver- and muscle-specific enzymes in horses in Iceland or at 24 weeks following their importation to Germany [35]. Our study provides support for elevated CK activity in Icelandic horses. The upper reference limit in Icelandic horses $(6.52 \mu \mathrm{kat} / \mathrm{l}, \mathrm{CI}$ : 5.92-6.15) was approximately two times higher than for the general horse populations and about three times higher than that found for horses in general in one study [6]. It compares well to several other studies $[6,10,11]$. It is, however, lower than the upper RL found by Gieseler with the same method $(11.14 \mu \mathrm{kat} / \mathrm{l})$ [4]. The reasons for these high $\mathrm{CK}$ activities are not clear, but an increased muscle mass in relation to the body mass [36], different 
serum isoenzyme CK patterns [37], or a tendency to form macroenzyme complexes that have a slower rate of elimination [38] could contribute to higher CK activities. Further studies are needed to clarify the cause(s).

The calculation of CI of the RLs should be part of the establishment of reference intervals [21]. CIs provide an estimate of the uncertainty of the limits and are generally narrower for large samples sizes [14]. For the nonparametric calculation of $\mathrm{CI}$, at least 120 individuals are required, if less are available, other methods like bootstrap have to be used [14]. This was only necessary for potassium in our study.

The width of the $90 \%$ CIs calculated in this study, is not described in detail in the ASVCP online guidelines, but is described in the CLSI guidelines [21] and by Friedrichs et al. [15]. The CI width exceeded 0.2 in 9/26 (34.6\%) of haematology analytes for at least one RL. This occurred most frequently with small fractions (differential cell count percentages), where effective outlier treatment was not possible. In other cases, the deviations are small and sometimes could be caused by the rounding of the figures $(\mathrm{MCV})$.

In $2 / 24$ ( $8.3 \%)$ of biochemistry analytes the CI width exceeded the recommended value. In the case of phosphorus, both RLs, in the case of iron only the lower RL was affected. This could have been caused by the rounding of the figures within the LIMS. To improve the CI width and increase confidence in the validity of the reference interval, additional individuals could be added to the analysis.

The results highlight the difficulties of comparing the RIs generated in this study with other RIs published for Icelandic horses and for other breeds. These comparisons were complicated by the use of different analytical and statistical methods, as well as the different sizes and composition of the reference populations. The recently published guidelines for the establishment of RIs in veterinary medicine were comprehensive and could be easily applied. Following them as closely as possible, will facilitate the comparison of RIs in the future. Careful scrutiny of the sources of RIs and the reference population, collection conditions, analytical conditions and statistical methods is needed to determine if they may be suitable for transference validation and to determine if references intervals may need to be generated de novo for a particular breed and/or practice population.

Considering the tradition of veterinary laboratory testing it is amazing that somewhat arbitrarily established RI's have been of clinical utility at all. Furthermore it is not clear if breed specific partitioning of RIs will improve clinical decisions and patient care as slight differences in RIs may not alter the clinical interpretation and decisionmaking process. Information on biologic variation that may help determine the significance of changes in patient data is scarce or absent for equine laboratory analytes. Only through continued experience with and analysis of data for breed-specific RIs will we be able to determine if breed-specific RIs may provide for improved clinical care for equine patients. The standardisation of the approach to reference interval generation, in accordance with the ASVCP guidelines, should help provide for a sound basis for comparisons of reference intervals. It will require time, however, for studies to be done using this standard approach.

\section{Additional file}

Additional file 1: Figure S1. Additional material the example shows the differentials of 2 animals, both with $92 \%$ neutrophils (segs) and $8 \%$ lymphocytes. The first example with $4.0 \mathrm{G} / \mathrm{I} \mathrm{WBC}$ results in an absolute number of neutrophils WRI and a lymphopenia. In the second example with $25.0 \mathrm{G} / \mathrm{I} \mathrm{WBC}$ the result is a neutrophilia and an absolute number of lymphocytes WRI.

\section{Abbreviations}

ALT: Alanine aminotransferase; AP: Alkaline phosphatase; ASVCP: American Society for Veterinary Clinical Pathology; AST: Aspartate aminotransferase; $\mathrm{CH}$ : Cellular haemoglobin; CHCM: Corpuscular haemoglobin concentration; $\mathrm{Cl}(\mathrm{s})$ : Confidence interval(s); CK: Creatine kinase; CLSI: Clinical Laboratory Standards Institute; CV: Coefficient of variation; DGGR: 1,2-o-Dilauryl-rac-glycero glutaric acid-(6'-methylresorufin); DGKC: Deutsche Gesellschaft für klinische Chemie; EDTA: Ethylenediaminetetraacetate; GGT: $\gamma$-glutamyl transferase; GLDH: Glutamate hydrogenase; Hb: Haemoglobin; Hct: Haematocrit; IFCC: International Federation for Clinical Chemistry; ISE: Ion selective electrode; LDH: Lactate dehydrogenase; LIMS: Laboratory Information and Management System; LRL: Lower reverence limit; MCH: Mean cellular haemoglobin; MCHC: Mean cellular haemoglobin concentration; MPV: Mean platelet volume; MP: Myeloperoxidase; MPXI: Myeloperoxidase index; PLT: Platelets; QC: Quality control; RBC: Red blood cells; RDW: Red blood cell distribution width;

RI(s): Reference interval(s); RL(s): Reference limit(s); RPM: Rotations per minute; TEa: Total allowable error; TEO: Total observed error; URL: Upper reference limit; WBC: White blood cells.

\section{Competing interests}

The study was financed, monitored and conducted solely by In Vitro Veterinary Laboratories. The authors have no financial or personal relationship with people or organisations that could inappropriately influence or bias the content of this paper.

\section{Authors' contributions}

$J$ initiated, planned and coordinated the study. She partly organised the blood samples and helped with the clinical examination, sampling and initial data recording. BR partly organised the blood sampling, was responsible for the clinical exam and took the blood samples. EL and JF collected data, performed the analysis as well as interpreted and presented the results. EL drafted the manuscript based upon the diploma thesis of JF. IS helped with the conduction of data-analysis and with the data interpretation, she also supervised JF's diploma thesis. All authors have read and approved the final version of the manuscript.

\section{Acknowledgements}

The authors wish to thank G. Kirtz and P. Ludwig for their competent technical assistance. They wish to thank Dr. K. Freeman for carefully editing the English and for a number of valuable suggestions. The authors further wish to thank G. Prechtl (Siemens Healthcare Diagnostics, Austria) for the help with the ADVIA cytograms' interpretation. 


\section{Author details}

${ }^{1}$ In Vitro Veterinary Laboratories, Rennweg 95, 1030 Vienna, Austria.

${ }^{2}$ Tierärztliche Praxis, Heiligenbrunnerg. 19, 7221 Marz, Austria. ${ }^{3}$ Clinical Pathology Platform, University of Veterinary Medicine, Veterinärplatz 1, 1210 Vienna, Austria.

Received: 7 March 2015 Accepted: 8 June 2015

Published online: 14 June 2015

\section{References}

1. Kristjansson T, Bjornsdottir S, Sigurdsson A, Crevier-Denoix N, Pourcelot P, Arnason T. Objective quantification of conformation of the Icelandic horse based on 3-D video morphometric measurements. Livest Sci. 2013;158:12-23.

2. Björnsson GB, Sveinsson HJ. The Icelandic horse. 2nd ed. Reykjavik: Edda Publishing; 2007. p. 20-33.

3. Lorange JB. WorldFengur: The studbook of origin on the Icelandic horse. WF Meeting Malmö. 2013. http://www.feiffengur.com/documents/ WorldFengur_JBL.pdf. Accessed 21st May 2015.

4. Petersen J. Genome-wide analysis reveals selection for important traits in domestic horse breeds. PLSO Genet. 2013. doi: 10.1371/journal.pgen.1003211.

5. Gieseler T. Referenzwerte beim Pferd. Leipzig: Disseration, Vet Med Leipzig, Leipzig; 2012.

6. Grimminger-Heigl G. Referenzbereiche in der Labordiagnostik beim Pferd (Blutglukose, Gesamteiweiß, CK, AST, AP, LDH, a-HBDH, G-GT, GLDH). Munich: Dissertation, Ludwig-Maximilian University; 1993.

7. Mayer J. Referenzbereiche in der Hämatologie beim Pferd. Munich: Dissertation, Ludwig-Maximilian University; 1994.

8. Lumsden $\mathrm{JH}$, Rowe R, Mullen K. Hematology and biochemistry reference values for the light horse. Can J Comp Med. 1980;44:32-42.

9. Takasu M, Nagatani N, Tozaki T, Kakaoi H, Maeda M, Murase T, et al. Hematological and biochemical reference values for the endangered Kiso horse. J Equine Sci. 2013;24:75-8.

10. Klingelhöfer K. Muskelenzymaktivitäten (AST, CK, LDH) und Laktatgehalte beim Islandpferd. Ein Beitrag zur Referenzbereichsdiskussion. Munich: Dissertation, Ludwig-Maximilian University; 1998.

11. Unkel M. Die Aktivität der Enzyme GOT (AST), CK, y-GT, LDH und GPT (ALT) im Blutserum von Islandpferden. Tierarztl Umsch. 1984:39:697-702.

12. Unkel M. Die Konzentration von Gesamteiweiß, Harnstoff, Triglyzeriden, Gesamtbilirubin und Cholesterin im Blutserum von Islandpferden. Tierarztl Umsch. 1984;39:781-90.

13. Unkel M. Die Konzentration von Kalium, Kalzium, Magnesium, Natrium und anorganischem Phosphat im Blutserum von Islandpferden. Tierarztl Umsch. 1984;39:989-94.

14. ASVCP Quality Assurance and Laboratory Standards Committee (QALS). Guidelines for the determination of reference intervals (RI) in veterinary species. http://www.asvcp.org/pubs/qas/index.cfm Guidelines For ASVCP website.pdf (2011). Accessed 21 May 2015.

15. Friedrichs KR, Harr KE, Freeman KP, Szladovits B, Walton RM, Barnhart KF, et al. ASVCP reference interval guidelines: determination of de novo reference intervals in veterinary species and other related topics. Vet Clin Pathol. 2012:41:441-53.

16. Giordano A, Rossi G, Pieralisi C, Paltrinieri S. Evaluation of equine hemograms using the ADVIA 120 as compared with an impedance counter and manual differential count. Vet Clin Pathol. 2008:37:21-30.

17. Hooijberg EH, Leidinger EF, Schwendenwein I. Comparison of total allowable and total observed error for two chemistry analysers. Copenhagen: ISACP Proceedings; 2014.

18. Nabity MB, Camus MS, Harr KE, Flatland B, Freeman K, Vap LM. Determination of allowable total error for hematology and coagulation measurands. Vet Clin Pathol. 2014;42 Suppl 4:E1-19.

19. Harr KE, Flatland B, Nabity M, Freeman KP. ASVCP guidelines: allowable total error quidelines for biochemistry. Vet Clin Pathol. 2013:42:424-36.

20. Geffré A, Concordet D, Braun J-P, Trumel C. Reference value advisor: a new freeware set of macroinstructions to calculate reference intervals with Microsoft Excel. Vet Clin Pathol. 2011;40:107-12.

21. Horowitz GL, Boyd JC, Ceriotti F, Garg U, Altaie S, Pesce A, et al. Defining, establishing, and verifying reference intervals in the clinical laboratory; proposed guideline. 3rd ed. USA: CLSI Document C28-P3; 2008.

22. Seiser M, Strasser A, Hofbauer B. Der Einfluss von Alter und Geschlecht auf diagnostisch wesentliche Blutparameter bei Islandpferden. Tierarztl Umsch 2001;29:324-31.
23. Árnason T, Sigurðsson Á, Lorange JB. International genetic evaluations of the Icelandic horse and genetic connectedness between countries. 8th Word Congress on Genetics Applied to Livestock Production. Belo Horizonte, MG, Brasil. August 13-18. 2006. http://www.feiffengur.com/documents/ WorldFengur_JBL.pdf. Accessed 21 May 2015.

24. Geffré A, Friedrichs K, Harr K, Concordet D, Trumel C, Braun J-P. Reference values: a review. Vet Clin Pathol. 2009;38:288-98.

25. Sharkey L, Gjevre K, Hegstad-Davies R, Torres S, Munoz-Zanzi C. Breed-associated variability in serum biochemical analytes in four large-breed dogs. Vet Clin Pathol. 2009;38:375-80

26. Satué K, Muñoz A, Gardón JC. Interpretation of alterations in the horse erythrogram. J Hematol Res. 2014;1:1-10

27. Mayer J. Hämatologische Referenzwerte bei Pferden. Munich: Dissertation, Ludwig-Maximilian University; 1994.

28. Jones AR, Twedt D, Hellman R. Absolute versus proportional differential leucocyte counts. Clin Lab Haematol. 1995;17:115-23.

29. Etzell JE. For WBC differentials, report absolute numbers. 2010. http:// www.captodayonline.com/Archives/0310/0310d_for_wbc_differentials.html. Accessed 21 May 2015.

30. Schwarz BC, van den Hoven R, Schwendenwein I. Diagnostic value of the neutrophil myeloperoxidase index in horses with systemic inflammation. Vet J. 2012;191:72-8.

31. Hooijberg EH, van den Hoven R, Tichy A, Schwendenwein I. Diagnostic and predictive capability of routine laboratory tests for the diagnosis and staging of equine inflammatory disease. J Vet Intern Med. 2014;28:1587-93.

32. Leidinger $\mathrm{E}$, Prechtl G, Figl J, Leidinger J. Monocytes in Icelandic horses: comparison between automatic gating by the Advia 2120i, a manual gating method, and microscopic differentiation. Comp Clin Path. 2015. doi: 10.1007/s00580-015-2080-5

33. Stockham SL, Scott MA. Monovalent electrolytes and osmolarity. In: Stockham SL, Scott MA, editors. Fundamentals of veterinary clinical pathology. Ames lowa: Blackwell publishing; 2008. p. 514.

34. Stefánsdóttir GJ, Ragnarsson S, Gunnarsson V, Jansson A. Physiological response to a breed evaluation field test in Icelandic horses. Animal. 2014;8:431-9.

35. Coenen M, Vervuert I, Braun S. Leber- und Muskelenzymaktivitäten von Islandpferden in Island und nach Import in Deutschland - 2. Mitteilung. Pferdeheilkunde. 2004;20:31-6.

36. Brancaccio P, Nicola Maffulli N, Limongelli FM. Creatine kinase monitoring in sport medicine. Br Med Bull. 2007;81 and 82:209-30.

37. Hatzipanagiotou A, Lindner A, Sommer H. LDH und CK Isoenzymmuster im Blutplasma von Pferden mit erhöhten CK, LDH und AST-Aktivitäten. Dtsch Tierarztl Wochenschr. 1991;98:284-6

38. Remaley AT, Wilding P. Macroenzymes: biochemical characterization, clinical significance, and laboratory detection. Clin Chem. 1989;35:2261-70.

\section{Submit your next manuscript to BioMed Central and take full advantage of:}

- Convenient online submission

- Thorough peer review

- No space constraints or color figure charges

- Immediate publication on acceptance

- Inclusion in PubMed, CAS, Scopus and Google Scholar

- Research which is freely available for redistribution 